\title{
EFFECT OF COPPER ON PROPERTIES OF FINE-GRAINED LOW-CARBON BORON STEEL
}

\author{
Jaromir DLOUHY, Pavel PODANY, Zbysek NOVY
}

COMTES FHT a.s., Dobrany,Czech Republic, EU, jaromir.dlouhy@comtesfht.cz

https://doi.org/10.37904/metal.2019.803

\begin{abstract}
Low carbon steels are used in variety of structural states. One of the most used is fine grained dual or multiphase structure with prevailing ferrite. Martensite/austenite islands forms rest of the structure. At least two of the phases - pearlite, bainite, martensite and rest austenite - occur in multi-phase steels. Main strengthening mechanisms are grain refinement and the hard phase content. The mostly ferritic soft matrix ensures sufficient plasticity. The constraining phenomena is cohesion of soft ferrite and the hard phase for the steel performance. Voids open upon deformation at the boundary between these constituents and lead to fracture. The difference in strength can be reduced by softening of the hard phase or by strengthening the ferrite. Copper alloying has possibility to do ferrite strengthening by precipitation. The experimental steel was subjected to controlled rolling to achieve dual- or multi-phase structure. Deformation in intercritical region resulted in fine ferritic matrix. Samples were subsequently quenched in water to transform remaining austenite into hard martensite or bainite. The delay between rolling and quenching gave opportunity for $\mathrm{Cu}$ to precipitate in freshly-formed ferrite and strengthen it. This approach leaves opportunity to gain precipitation strengthening in soft phase with no loss in hard phase strength. This is different from conventional quenching and tempering approach. The tempering acts also as precipitation hardening, but the tempering decreases strength of martensite in far higher rate than Cu precipitation can strengthen the ferritic matrix.
\end{abstract}

Keywords: Steel, Copper precipitation, Controlled rolling, Dual steel

\section{INTRODUCTION}

Copper is almost insoluble in ferrite at room temperature [1]. The solubility rises with increasing temperature and reaches maximum value $2 \%$ at $850^{\circ} \mathrm{C}$ (all element contents are given in mass \%). The austenite has $\mathrm{Cu}$ solubility $2.5 \%$ at that temperature. Therefore, there is a possibility for precipitation hardening - by $\mathrm{Cu}$ dissolution in ferrite at high temperature, rapid cooling into region of supersaturated $\mathrm{Cu}$ solution in ferrite and precipitation of $\mathrm{Cu}$ in form of nanometric particles. Structure refinement, which is essential for production of high-strength steels, is often ensured bz thermomechanical processing [2].

Controlled rolling is a production process which offers an opportunity to exploit copper precipitation phenomena without adding any processing stage to the steel sheet production. This process is already used to produce high strength steel sheets with ferritic-martensitic microstructure [3]. The steel is hot rolled with final rolling temperature close to the temperature $\mathrm{A} 1$. The sheet has fine ferritic-austenitic structure after the rolling and undergoes water quenching to transform austenite into martensite/austenite islands (M/A). Adding $\mathrm{Cu}$ into steel composition requires only tuning of process parameters to ensure enough time for $\mathrm{Cu}$ to form nanometric precipitates in ferrite grains $[4,5]$.

Dual steel production was designed as rolling below $A_{3}$ - at temperatures ranging from $A_{1}$ to $A_{1}+50^{\circ} \mathrm{C}$. Boron steels was used in the experiment - one alloyed by $1 \% \mathrm{Cu}$ and one reference steel without $\mathrm{Cu}$ addition. Boron alloying was chosen to slow down proeutectoid ferrite and pearlite formation. The rolling should be performed ideally on the structure of undercooled austenite. This ensures fine ferritic-austenitic structure after the rolling. There was a delay between rolling and quenching at temperatures from $590^{\circ} \mathrm{C}$ to $650{ }^{\circ} \mathrm{C}$. The delay was from 11 to $25 \mathrm{sec}$. long. Any Cu precipitation occurring during that hold increases yield strength of the ferrite and can be measured by tensile testing. 


\section{EXPERIMENT}

There were two experimental steels used for the experiment. Both were casted in induction vacuum furnace under argon atmosphere. Chemical composition of the steels is in Table 1. The size of the batches was 500 $\mathrm{kg}$ and they were processed by forging and hot rolling into $5 \mathrm{~mm}$ thick sheets. Samples for the experiment were cut from the sheets. The samples had length $220 \mathrm{~mm}$, width $75 \mathrm{~mm}$ and their longest dimension was in the sheet rolling direction.

Table 1 Chemical composition of the experimental materials in mass \%.

\begin{tabular}{|c|c|c|c|c|c|c|c|c|}
\hline Material & $\mathbf{C}$ & $\mathbf{M n}$ & $\mathbf{C u}$ & $\mathbf{S i}$ & $\mathbf{B}$ & $\mathbf{T i}$ & $\mathbf{N}$ & $\mathbf{F e}$ \\
\hline $0 \mathrm{Cu}$ & 0.22 & 0.98 & 0.12 & 0.073 & 0.0014 & 0.022 & 0.0056 & bal. \\
\hline $1 \mathrm{Cu}$ & 0.21 & 0.98 & 1.08 & 0.081 & 0.0014 & 0.025 & 0.0063 & bal. \\
\hline
\end{tabular}

Controlled rolling was performed by experimental rolling mill in duo configuration. The rolls had diameter 550 $\mathrm{mm}$ and the rolling speed was $0.25 \mathrm{~m} / \mathrm{s}$. Samples were covered by protective coating against decarburization and heated in the atmospheric electric furnace. Cooling of the samples to the rolling temperature ( $\mathrm{Td})$ and to the quenching temperature $(\mathrm{Tq})$ was in still air. Final quenching was performed in water bath. Schematic representation of regimes is in Figure 1 as well as times and temperatures for each regime. Samples labelling is described there too.

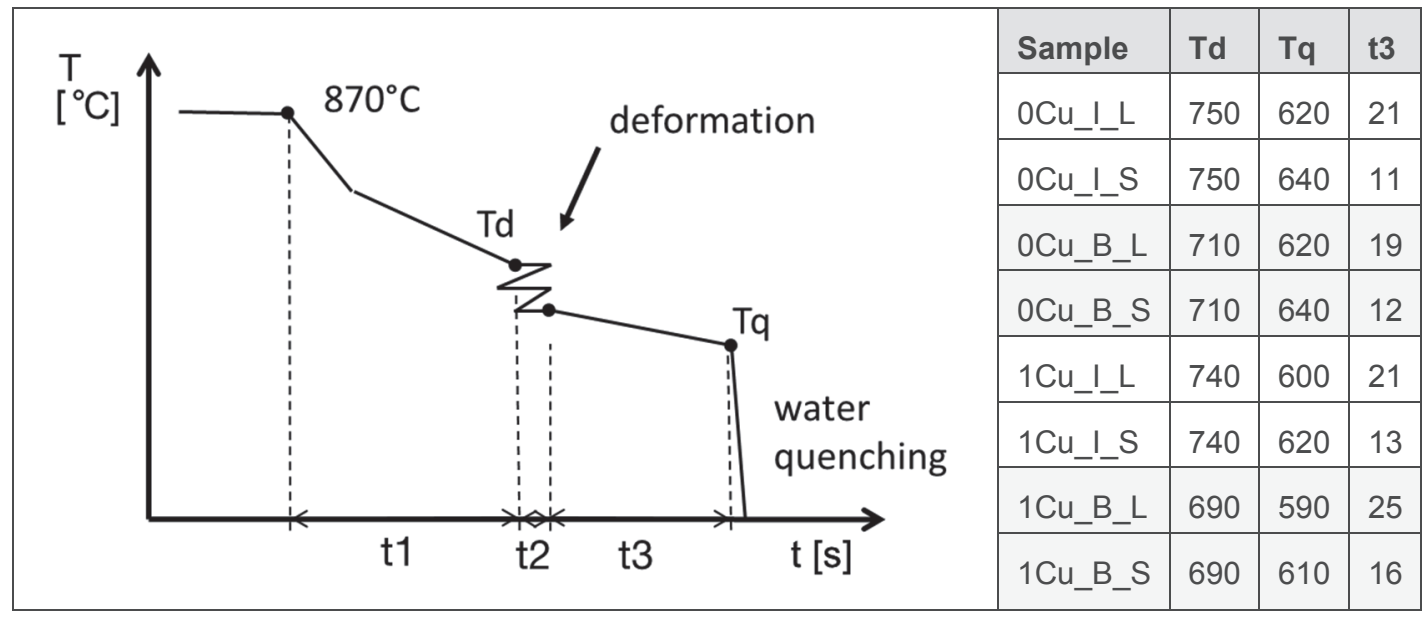

Figure 1 Scheme of the regimes and parameters for each sample. Sample labelling consists of material sign

$(0 \mathrm{Cu}$ or $1 \mathrm{Cu}$ ), temperature designation (I for intercritical deformation, $\mathrm{B}$ for deformation below critical temperature) and hold before quenching designation ( $\mathrm{L}$ for the long, $\mathrm{S}$ for the short one). Time $\mathrm{t} 1$ varied according to the Td from 12 to $20 \mathrm{sec}$, t2 was $1 \mathrm{sec}$.

The rolling generally consisted in sample heating to the temperature $870{ }^{\circ} \mathrm{C}$ for 20 minutes for complete austenitization. Sample was removed from the furnace and let to cool down to required rolling temperature. The temperature was measured by pyrometer. Two Td were chosen for each material - one in intercritical region (I) and one slightly below $A_{c 1}$ temperature (B). The deformation was performed in one reduction from 5 $\mathrm{mm}$ sheet into $3.1 \mathrm{~mm}$ thickness (i.e. $38 \%$ reduction). The sample was immediately removed from the mill and quenched after certain delay. Two delays were chosen - short one (S) between 11 and 16 sec. and longer one $(L)$ between 21 and $25 \mathrm{sec}$.

Specimens for the mechanical testing were cut from the samples. Specimens had gauge length $20 \mathrm{~mm}$ and width $4 \mathrm{~mm}$. Quasistatic tensile test was performed according to standard EN ISO 6892-1. Proof stress $R_{p 0.2,}$ tensile strength $R_{m}$, total elongation $A_{5}$ and reduction of area $Z$ were measured. Three specimens were tested from each sample. 
Metallography was performed on longitudinal sections. They were prepared by mechanical grinding and polishing. Final polishing was performed by colloidal silica with average particle size $0.05 \mu \mathrm{m}$. Microstructure was revealed by Nital etchant. The microstructure was observed in scanning electron microscope (SEM) JEOL IT-500HR. Backscattered electron signal proved to be the most revealing, particularly to distinguish between ferrite grains and martensite/austenite islands $(M / A)$.

\section{RESULTS AND DISCUSSION}

The microstructure of all samples was mostly ferritic. The other constituents were M/A islands and pearlite.

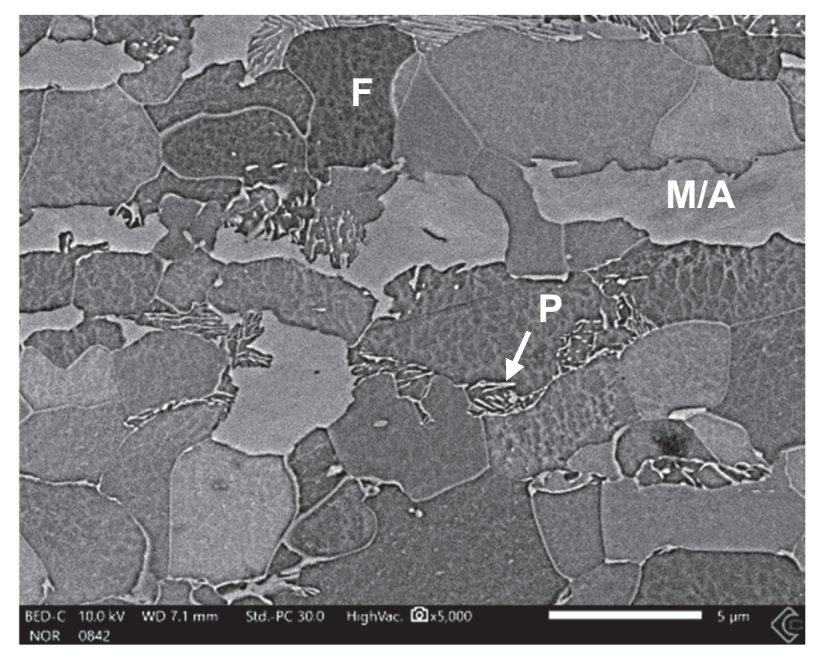

a) OCu_I_L

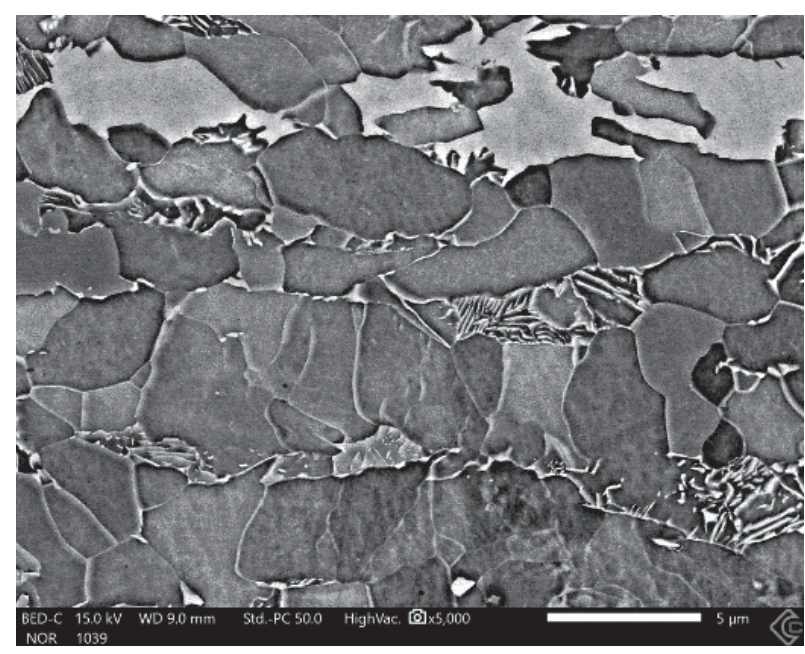

c) OCu_B_L

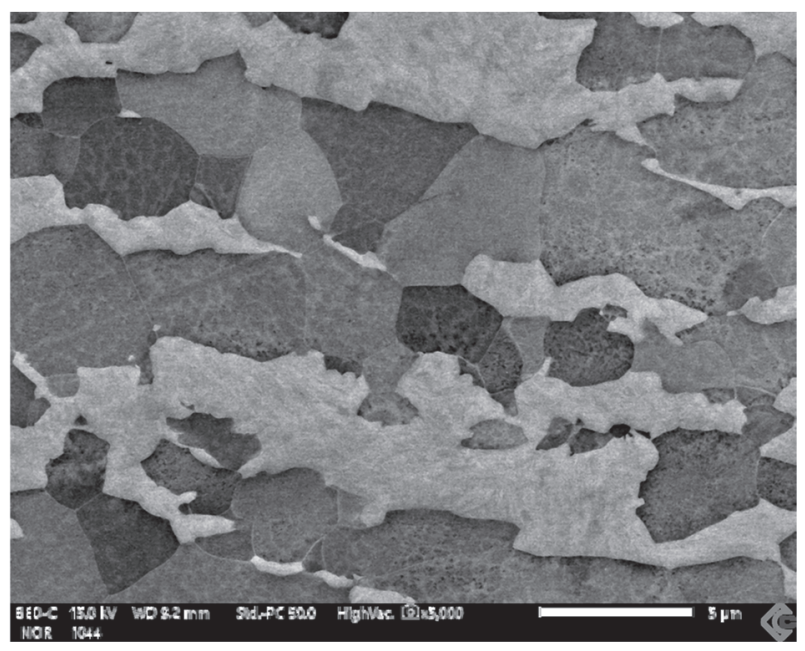

b) 0Cu_I_s

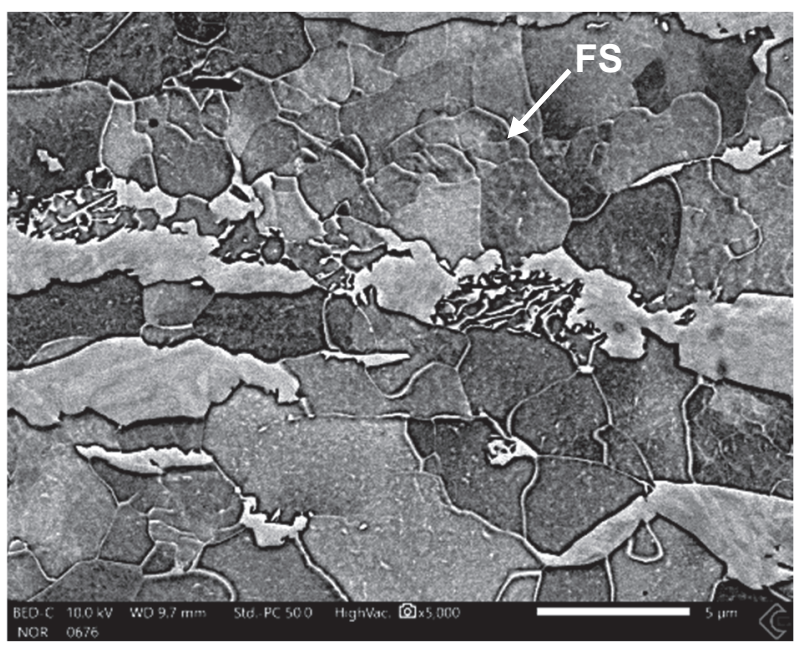

d) 0Cu_B_S

Figure 2 Steel without $\mathrm{Cu}$. M/A islands are the bright regions. M/A - martensite/austenite islands; P - pearlite, F-ferrite, FS - ferrite substructure.

These phases were distributed in bands parallel with rolling direction and partially also randomly among ferritic grains. This is visible in micrographs in Figures 2 and 3. Ferritic grains were equiaxed. Ferrite grains in samples "l" (after intercritical deformation) exhibited no visible substructure within ferritic grains. They appeared fully recrystallized. Samples "B" with lower Td exhibited possibly some subgrain boundaries in ferrite grains and the grain boundaries were also not as straight as in case of "l" samples. This indicates that the ferrite recrystallization was not completed at the lower temperature before quenching. 


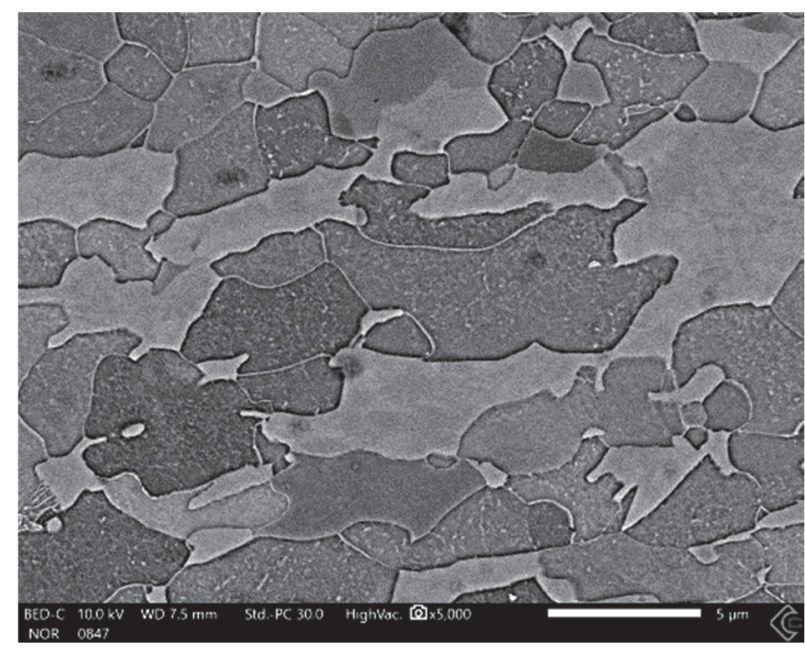

a) $1 \mathrm{Cu}$ I_L

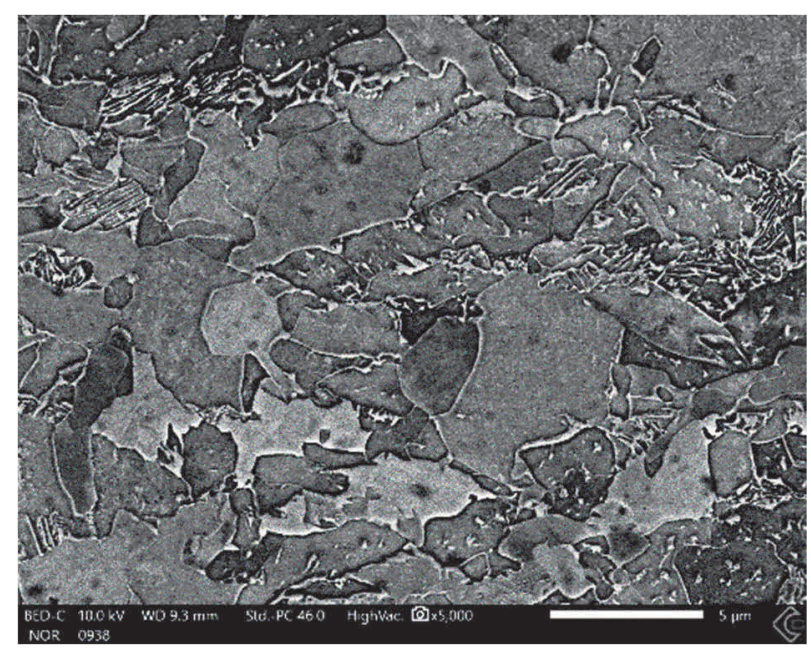

c) 1 Cu_B_L

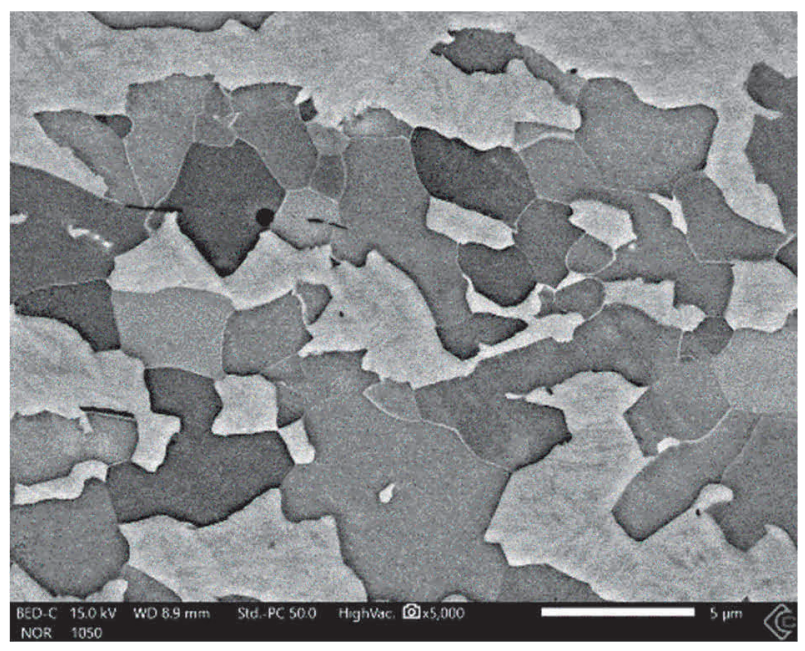

b) 1Cu_ISS

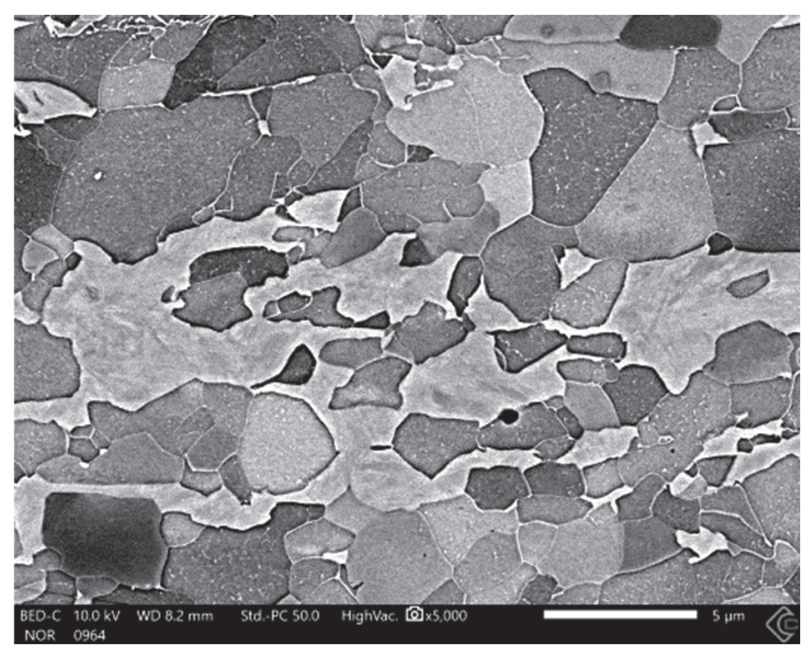

d) 1Cu_B_S

Figure 3 Steel with $\mathrm{Cu}$ - microstructures of individual regimes.

Phase content is given in Table 2. Micrographs for the quantification were taken in the depth roughly $0.8 \mathrm{~mm}$ below the sheet surface. Microstructure close to the surface was different - finer ferrite grains and lower amount of martensite. This was observed to the depth roughly $0.4 \mathrm{~mm}$. There was also decarburized layer $0.1 \mathrm{~mm}$ thick on both sheet surfaces. However, this structural heterogeneity was very similar for all sheets. The influence on mechanical properties can be assumed as roughly equal for all samples. Mechanical properties can be attributed to the structures in Figures 1 and $\mathbf{2}$ with the remark, the surface layer with different structure alters them approximately the same way for all samples.

Results of the tensile test are in the Table 2. Tensile strength showed correlation with the structural composition. Higher amount of M/A islands lead to higher strength, presence of pearlite reduced it. Proof stress $\mathrm{R}_{\mathrm{p} 0.2}$ was not affected largely by the form of hard structure constituent - whether it was M/A or pearlite. Much more important seemed to be the state of ferrite. Fully recrystallized "I" samples exhibited generally lower $\mathrm{R}_{\mathrm{p} 0.2}$ than "B" samples with substructure observed within ferrite grains.

There was also difference between the materials. Longer hold meant decrease of $R_{p 0.2}$ for material without copper. This is expected behaviour as the structure had more time for recover and recrystallization during

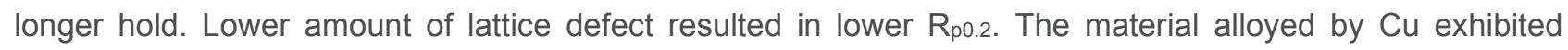


opposite trend. Longer hold increased $\mathrm{R}_{\mathrm{p} 0.2}$ for both deformation temperatures. This increase can be attributed to the precipitation of $\mathrm{Cu}$ precipitates within the ferrite.

The best results were obtained for the $1 \mathrm{Cu}$ samples deformed below $\mathrm{A}_{1}$ temperature. $\mathrm{R}_{\mathrm{p} 0.2}$ rose by $40 \mathrm{MPa}$ within $9 \mathrm{sec}$ hold prolongation with no decrease in total elongation and increase of area reduction.

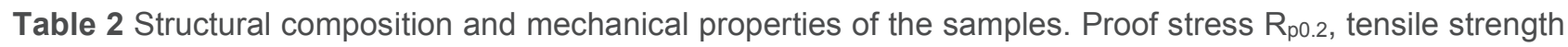
$R_{m}$, total elongation $A_{5}$ and reduction of area $Z$.

\begin{tabular}{|c|c|c|c|c|c|c|c|}
\hline \multirow[t]{2}{*}{ Regime } & \multicolumn{3}{|c|}{ Phases [vol. \%] } & \multicolumn{4}{|c|}{ Mechanical properties } \\
\hline & Ferrite & M/A & Pearlite & $\mathbf{R}_{\mathrm{p} 0.2}[\mathrm{MPa}]$ & $\mathbf{R}_{\mathrm{m}}[\mathrm{MPa}]$ & $\mathrm{A}_{5}[\%]$ & $\mathrm{Z}$ [\%] \\
\hline OCu_I_L & 80 & 5 & 15 & 479 & 830 & 12.5 & 24 \\
\hline OCu_I_S & 70 & 30 & 0 & 487 & 1022 & 11.9 & 18 \\
\hline OCu_B_L & 80 & 5 & 15 & 536 & 590 & 24.0 & 46 \\
\hline OCu_B_S & 75 & 20 & 5 & 598 & 687 & 15.6 & 37 \\
\hline 1Cu_I_L & 70 & 30 & 0 & 604 & 932 & 10.6 & 19 \\
\hline 1Cu_I_S & 60 & 40 & 0 & 586 & 1052 & 13.2 & 17 \\
\hline 1Cu_B_L & 75 & 5 & 20 & 672 & 843 & 10.3 & 27 \\
\hline 1Cu_B_S & 60 & 35 & 5 & 633 & 970 & 10.6 & 21 \\
\hline
\end{tabular}

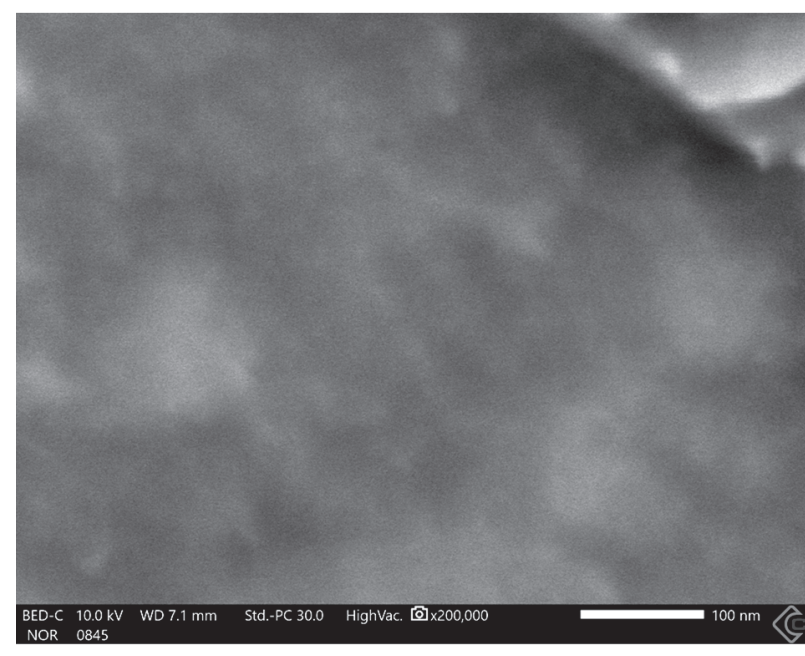

a) $0 \mathrm{Cu}$ IIL

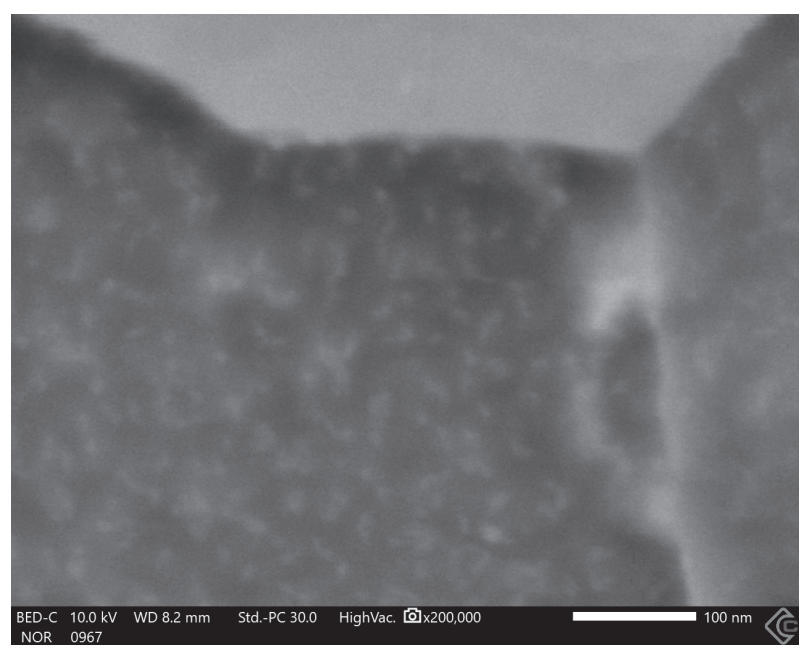

b) 1Cu_IL

Figure 4 High-resolution SEM. Scale bars have $100 \mathrm{~nm}$. Distinct bright particles are visible in ferrite grain interior in panel b).

The high-resolution SEM observation was in agreement with tensile test results. Figure 4 shows the interior of ferritic grains for both experimental materials. The brighter spots - most probably the Cu precipitates - were observed in all samples from $1 \mathrm{Cu}$ steel. There were no such distinct features in the 0Cu steel. However, precise characterization could be achieved only by means of transmission electron microscopy.

\section{CONCLUSION}

Dual and multi-phase structures were prepared by controlled rolling. Proof stress of the samples was mostly determined by state of the ferrite and tensile strength mostly by amount of martensite in the structure. Presence of pearlite instead of martensite significantly reduced tensile strength. 
Copper alloying caused higher austenite stability and the steel tended less to form pearlite during the hold after rolling. There was also strengthening observed in copper alloyed steel with longer hold at temperature range $600-640{ }^{\circ} \mathrm{C}$. Prolongation of the hold resulted in proof stress increase with simultaneous increase of plasticity and reduction of tensile strength. Copper precipitation had observable influence on properties in time scale 10-25 sec at the holding temperature.

\section{ACKNOWLEDGEMENTS}

The results presented in this paper arose under the project "Synergy of precipitation, deformation and transformation hardening in steels with higher copper content" No. 17-19002S funded by Czech Science Foundation.

These results were also created under the project entitled Development of West-Bohemian Centre of Materials and Metallurgy No.: L01412, financed by the Ministry of Education, Youth and Sports of the Czech Republic.

\section{REFERENCES}

[1] LIU, C. T., JIAO, Zengbao and LHUAN, Jh. Copper-rich nanoclusters: ferritic steels strengthened. In: COLÁS, Rafael and TOTTEN, George E., eds. Encyclopedia of Iron, Steel, and Their Alloys. Taylor \& Francis, 2015, pp. 875-886, DOI: 10.1081/E-EISA-120052707

[2] PODANY, Pavel., MARTINEK, Petr. Thermomechanical processing of micro-alloyed steel. Materiali in Tehnologije. 2014. vol. 48, no. 6, pp. 855-859.

[3] ZHAO, Jingwei and JIANG, Zhengzi. Thermomechanical processing of advanced high strength steels. Progress in Materials Science. 2018. vol. 94, pp. 174-242. DOI: 10.1016/j.pmatsci.2018.01.006

[4] LIU, Quingdong and LIU, Wending. Correlation of Cu precipitation with austenite-ferrite transformation in a continuously cooled multicomponent steel: An atom probe tomography study. Journal of Materials Research. 2012. vol. 27, no. 7, pp. 1060-1067. DOI: 10.1557/jmr.2012.54

[5] PHANIRAJ, M. P., SHIN, Young-Min, LEE, Joonho, GOO, Nam. H., KIM, Dong-lk, Suh, Jin-Yoo, JUNG, WooSang, SHIM, Jae-Hyeok, CHOI, In-Suk. Development of high strength hot rolled low carbon copper-bearing steel containing nanometer sized carbides. Materials Science \& Engineering A. 2015. vol. 633, pp. 1-8. DOI: 10.1016/j.msea.2015.02.067 